\title{
Objeto de Aprendizagem de Números Complexos com aplicações na área técnica em eletroeletrônica
}

José Eustáquio Pinto Zeustaquio13@gmail.com 0000-0001-9064-128x Universidade Estadual de Educação de Minas Gerais - FAE, Belo Horizonte, Minas Gerais, Brasil.

João Bosco Laudares jblaudares@terra.com.br 0000-0003-3624-3402 Pontifícia Universidade Católica, Belo Horizonte, Minas Gerais, Brasil.

\section{RESUMO}

Neste artigo, apresentamos resultado de uma pesquisa de Mestrado, apoiada pelo Projeto de Pesquisa "Objetos de aprendizagem para o ensino de matemática na Educação Profissional Técnica de Nível Médio", edital 13/2012, financiado pela FAPEMIG, sendo desenvolvido no período 2012/ 2016. O Objeto de Aprendizagem, denominado "Descomplicando os complexos", foi criado em apoio ao professor de matemática e aos estudantes do ensino médio e técnico. Foi estruturado em seis atividades, sendo as duas primeiras sem aplicações técnicas, de forma a atender estudantes do ensino médio regular, e as demais direcionadas aos cursos médios profissionais técnicos com aplicações na área eletroeletrônica. Ficou referenciado teoricamente por parâmetros da Informática Educativa, especialmente, quanto a pressupostos conceituais e metodológicos de Objeto Aprendizagem e Sequência Didática. As atividades foram construídas com base nas representações algébricas e geométricas de pontos e vetores que representam números complexos, num contexto da interdisciplinaridade: Matemática e Eletricidade; assim os elementos dos circuitos são analisados por números complexos. Pelos resultados da aplicação experimental constatamos que a dinamicidade e interação dos estudantes proporcionadas pelo Objeto de Aprendizagem otimizaram o processo de aprendizagem.
\end{abstract}

PALAVRAS-CHAVE: Informática. Objetos de Aprendizagem. Números Complexos. 


\section{INTRODUÇÃO}

Neste texto apresentamos resultados da aplicação de duas atividades que compõem uma sequência didática, digital e interativa, que integram um objeto educacional, Objeto de Pesquisa de Mestrado Profissional.

O Objeto de Pesquisa da qual apresentamos alguns de seus resultados, tratase de elaboração e aplicação de Objetos de Aprendizagem (OA) para cursos médios e profissionais técnicos da área eletroeletrônica.

Foi apoiado pelo Projeto de Pesquisa "Objetos de aprendizagem para o ensino de matemática na Educação Profissional Técnica de Nível Médio", edital 13/2012, financiado pela FAPEMIG, sendo desenvolvido no período 2012/ 2016.

É direcionado ao estudante e professor de Matemática. Pela sua natureza, é um produto didático interdisciplinar. Para a elaboração do referido $\mathrm{OA}$, tivemos referenciais teóricos dos seguintes temas: Informática Educativa, Objetos de Aprendizagem, Sequência Didática e Ensino dos Números Complexos.

Entendemos que uso da tecnologia é um processo em transformação, e as inovações tecnológicas podem resultar em mudanças de todo um paradigma. A internet, rede mundial de computadores, é um dos principais exemplos disso. Além de transformar radicalmente a maneira das pessoas de se comunicarem, realizarem transações bancárias, efetuarem compras, anunciarem produtos entre outras atividades cotidianas, proporciona também uma mudança de paradigma pedagógico, ou seja, a maneira como as pessoas ensinam e aprendem. Consequentemente, uma transformação pode acontecer também na forma como materiais educacionais são desenvolvidos e oferecidos para aqueles que desejam aprender.

No que tange às possibilidades e potencialidades do uso da informática, no processo de ensino/aprendizagem, esta traz possibilidades de diversificação de métodos didáticos pois, Oliveira (2001, p.08)

"entre as contribuições da informática frequentemente enfatizadas por alguns especialistas na área de Informática na Educação está a de favorecer o trabalho do professor, enriquecendo e diversificando a sua forma de encaminhar o processo de ensino-aprendizagem."

Ao destacarmos a importância das TICs para a escola, enfatizamos a relevância do papel do professor nesse processo que, para Masetto (2013), assume o papel de mediador. Destacamos também que, embora o professor ainda desempenhe $o$ papel de especialista, que possui conhecimentos e experiências a comunicar, na maioria das vezes ele vai atuar como orientador das atividades do estudante, consultor, facilitador, planejador e dinamizador de situações de aprendizagem, trabalhando em equipe com os estudantes, buscando os mesmos objetivos.

A incorporação das TICs sem planejamento, de maneira subutilizada, pode não alterar o carácter expositivo da aula quando utilizada, simplesmente, para projetar num quadro ou parede a informação que outrora utilizava-se o giz ou pincel. Segundo Masetto (2013, p.142).

"trabalhar com tecnologias visando criar encontros mais interessantes e motivadores dos professores com os alunos não significa privilegiar a técnica de aulas expositivas e recursos audiovisuais, mais convencionais ou mais modernos, que são usadas para a transição de informações, conhecimentos, experiências." 
As TICs possibilitam o dinamismo que relaciona a álgebra e a geometria. Desta forma, optamos por criar uma ferramenta informatizada, denominada Objeto de Aprendizagem, que proporcione autonomia e interação com o estudante tendo o professor como um mediador. Então, no contexto da informática educativa, identificamos um instrumento com potencial para uma performance interativa conteúdo-docente-estudante no processo ensino e aprendizagem.

Verificamos, a partir de levantamento bibliográfico do tema da pesquisa, que não há uma definição formal para Objetos de Aprendizagem. Mas vários conceitos são encontrados em artigos, dissertações, teses e livros especializados. Um conceito encontrado com maior frequência é de Wiley (2000), que apresenta objetos de aprendizagem como sendo qualquer recurso digital que possa ser utilizado para o suporte ao ensino.

O conceito de material pedagógico tradicional (rígido e estático) tem cedido espaço para os materiais digitais e interativos, com movimento e ação. Essa nova tendência credencia o OA com tais características a ser um bom modelo de material educacional na sociedade da informação em que vivemos. O termo OA surgiu no início do século XXI e, passou a ser utilizado para se referir a recursos digitais. Para Wiley (2000), OA são elementos de um novo tipo de instrução baseados em computadores criados em qualquer mídia ou formato: applet java; animação flash; vídeo ou áudio clip; foto; apresentação powerPoint; website. Podem exigir recursos de linguagens de programação.

É destacada também, sua versatilidade, quanto a possibilidade de sua utilização em diversos ambientes de aprendizagem, a característica de operabilidade. Além disso, possui a capacidade de renovar as práticas docentes por meio da interação com os objetos de estudo, permitindo aos professores e alunos criarem situações desafiadoras explorando conceitos específicos em matemática e em outras áreas do conhecimento.

A elaboração do OA apresentado neste artigo envolve o ensino dos números complexos com aplicações na área técnica em eletroeletrônica, e foi estruturado com parâmetros nos resultados de pesquisa, realizada por Laudares (1987), com o objeto de levantar os conteúdos do ensino médio e suas aplicações para o ensino técnico industrial, abrangendo todas as Escolas Técnicas Industriais Federais e CEFETs (Centros Federais de Educação Tecnológica) de todo Brasil. Esta investigação qualitativa teve como sujeitos cerca de 300 professores respondentes de questionário e, parte destes entrevistados. Ficou evidenciada a necessidade do estudo e aplicações dos números complexos, entre os vários conteúdos do ensino médio para a área eletroeletrônica. Em levantamento semelhante, em 2014, especificamente com professores do CEFET-MG, novamente ficou ressaltada a importância deste estudo.

Pesquisando as dificuldades/resistência dos alunos quanto ao estudo e aprendizagem deste conteúdo, devido à dificuldade de abstração, Spinelli (2009, p.5) entende que

"a escolha do caminho das necessárias abstrações envolve tomar a decisão de apresentar os "complexos" aos alunos, sem os "números". Ou seja, convém de início, deixar claro que os complexos não são importantes enquanto números, 
de serem utilizados como "operadores", capazes de gerenciar transformações isométricas no plano"

Para esse mesmo autor, ao compreender e operar com os números complexos com representação de vetor e executando rotações, reflexões e translações, haverá uma compreensão mais significativa desses números. Assim, múltiplas relações de significado entre os conceitos matemáticos, e também procedimentos matemáticos serão os elementos que alimentarão as abstrações.

A estratégia adotada na estruturação do OA foi a elaboração de atividades obedecendo a parâmetros metodológicos de sequências didáticas, conforme definição de Zabala (1998 p. 18) "um conjunto de atividades ordenadas, estruturadas e articuladas para a realização de certos objetivos educacionais, que têm um princípio e um fim conhecidos, tanto pelos professores como pelos alunos".

Segundo o mesmo autor, os tipos de atividades e, essencialmente, sua forma de articular são traços determinantes de muitas propostas didáticas. Possuem ênfase, no método: a natureza, a ordem e a proposta pedagógica inserida na sequência didática. Portanto a identificação das fases, das atividades e das relações que são estabelecidas são as características que levam à compreensão do valor educacional desta proposição metodológica da sequência didática e de conteúdo.

Assim, a sequência de conteúdo e a sequência didática se estruturaram na nossa proposta de uma forma que articularam os números complexos, numa interpretação geométrica e gráfica além da algébrica, com as aplicações técnicas em circuitos elétricos.

A linguagem computacional utilizada envolveu o uso dos softwares GeoGebra e ExeLearning ${ }^{1}$. Nas fases de desenvolvimento, cada item das atividades já elaboradas, era testado e revisado, as telas de animações eram colocadas à prova e, nesse momento, surgiam as sugestões e críticas relacionadas à didática utilizada, que contribuíram muito para o desenvolvimento do OA.

\section{OA DESCOMPLICANDO OS COMPLEXOS E ANÁLISE DA APLICAÇÃO.}

Apresentamos neste texto duas das seis atividades que compõem o $O A$, sendo uma delas sem aplicação e outra com aplicações em análise de circuitos elétricos.

A figura 1 mostra a tela inicial do OA Descomplicando os Complexos. O canto esquerdo da tela é reservado para visualização do menu de navegação. Clicando com o mouse no link "números complexos", o menu se expande mostrando os links de acesso às seis atividades que compõem o $O A$. 
Figura 1 - Tela inicial do OA Descomplicando os Complexos.

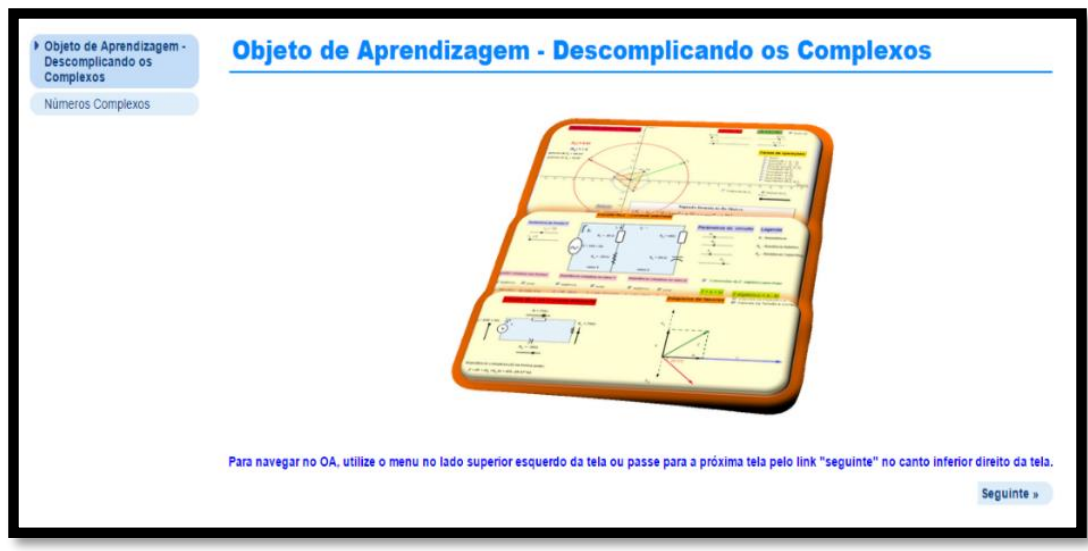

(Fonte: OA Descomplicando os Complexos)

As atividades foram criadas com a finalidade de compor uma sequência didática, em ambiente informatizado, para explorar o estudo dos números complexos com aplicações básicas em análise de circuitos de corrente alternada. Para cada atividade, foi criado um questionário de múltipla escolha com quatro opções de resposta.

Cada atividade é composta de um questionário de múltipla escolha e links que direcionam o estudante para o conteúdo teórico intitulado de "Apoio teórico" pertinente à atividade em questão. $\mathrm{O}$ objetivo foi o desenvolvimento de um $\mathrm{OA}$ que proporcionasse ao estudante um aprendizado para autonomia. Optamos por elaborar as atividades com questionários de múltipla escolha, dessa maneira, foi possível desenvolver mensagens com feedbacks dando retorno instantâneo ao estudante, quanto ao sucesso ou insucesso, ao optar por uma das quatro opções de resposta de cada item do questionário das seis atividades. No caso de insucesso, o estudante recebe o feedback com orientação didática que deve ser seguida antes do tentar novamente.

As duas primeiras atividades têm como objetivo o ensino dos números complexos sem aplicações, com foco nas propriedades matemáticas, sem aplicações do conteúdo da educação profissional técnica. Já nas quatro atividades seguintes, acontecem aplicações da teoria e operações envolvendo os números complexos na análise de circuitos elétricos. Dessa forma, objetivou-se criar um OA que possa ser utilizado tanto no Ensino Médio, referente às duas primeiras atividades, como no Ensino Médio Técnico, quanto às outras quatro atividades.

O OA foi testado por vinte (20) estudantes do segundo ano do Curso Técnico em Equipamentos Biomédicos, da área de eletroeletrônica, do Centro Federal de Educação Tecnológica de Minas Gerais (CEFET-MG) da unidade de Belo Horizonte.

Apresentamos a seguir os objetivos e metodologias assim como a análise dos resultados da aplicação da segunda e sexta atividade do OA desenvolvida.

Atividade 2: operações com números complexos.

Os objetivos desta atividade se resumem em: 
- operar algébrica e geometricamente com números complexos, envolvendo as operações: soma, subtração, produto escalar vetorial, quociente, potência e raízes.

- Identificar relações e verificar propriedades envolvendo módulos e argumentos das potências e raízes de números complexos.

A metodologia utilizada explora a dinamicidade algébrica e geométrica que a tela de animações proporciona e a disponibilidade de material teórico pertinente ao tema que conduzem o estudante ao aprendizado pelo comportamento geométrico dos vetores envolvendo as operações de soma, subtração, produto escalar de dois vetores, divisão, potenciação e radiciação de números complexos.

Nesta atividade, com foco nas operações entre números complexos, esperamos, pela dinamicidade algébrica e geométrica proporcionada pela tela de animações, ilustrada na figura 2 , que os estudantes possam responder um questionário de seis itens:

Figura 2 - Tela de animações do OA, Atividade 2.

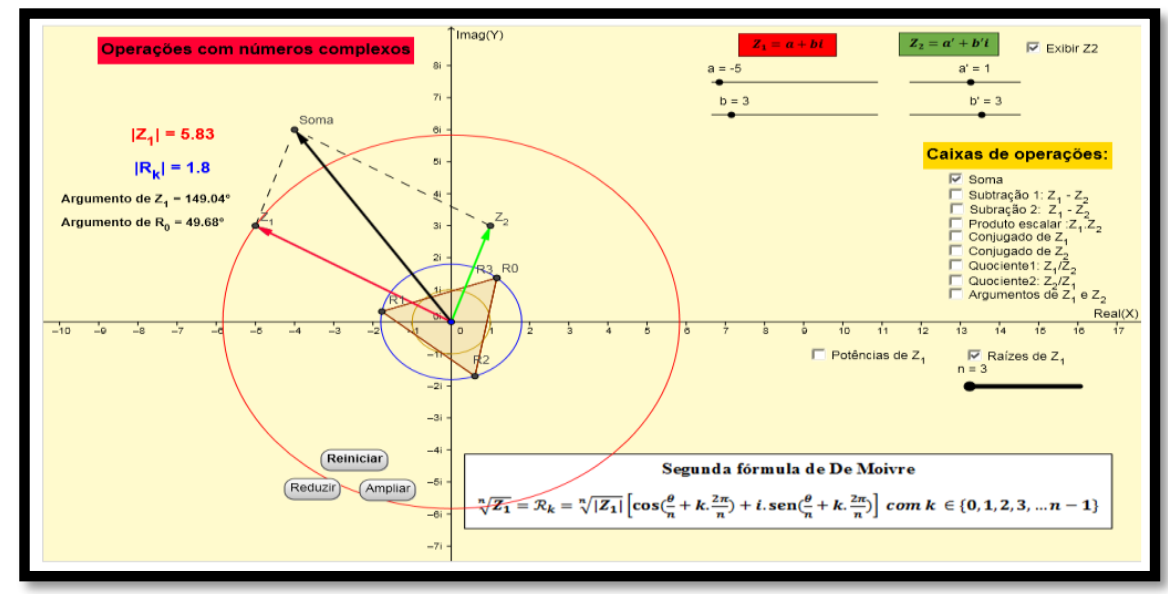

(Fonte: OA Descomplicando os Complexos)

Como exemplo representamos, na figura 3, o quinto item do questionário da Atividade 2. Nessa situação, foi marcada a opção correta e o OA forneceu o feedback ao estudante. 


\section{? Quinto item.}

Habilitando a caixa "Potências de $\mathrm{Z}_{1}$ " aparecerá na tela uma barra de controle deslizante que serve para alterar o valor do expoente n e uma imagem com a primeira fórmula de De Moivre e ao mesmo tempo a representação vetorial da potência de $Z_{1}$ que pode ser modificada quando se altera os parâmetros do ponto $Z_{1}$ ou o expoente

Observando a fórmula e o comportamento geométrico do vetor "Potência de Z equivale ao módulo de $Z_{1}$ elevado ao expoente $n$ e 0 argumento da "Potência de $Z_{1}$ " equivale ao argumento de $Z_{1} n$ ' vezes. Utilizando os recursos disponiveis na tela, qual das alternativas abaixo explica o comportamento geométrico quando elevamos a unidade imaginária (i) a um expoente natural $\mathrm{n}$.

(6)

a) 0 vetor unitário ganha uma rotação de $90^{\circ}$ no sentido horário a cada alteraçãa unitária e positiva do expoente n'

b) 0 vetor unitário ganha uma rotação de $180^{\circ}$ no sentido anti-horário a cada alteração unitária e positiva do expoente n'.

C c) 0 vetor unitário ganha uma rotação de $180^{\circ}$ no sentido horário a cada alteração unitária e positiva do expoente n'.

- d) 0 vetor unitário ganha uma rotação de $90^{\circ}$ no sentido anti-horário a cada alteração unitária e positiva do expoente n'

Parabéns! Continue assim

(Fonte: OA Descomplicando os Complexos)

O objetivo do quinto item é que o estudante entenda o comportamento geométrico do vetor que representa a potência de um número complexo, pela dinamicidade proporcionada pelas ferramentas desenvolvidas na tela de animações. Ao seguir o roteiro do enunciado, o estudante consegue visualizar a primeira fórmula de De Moivre: $\mathrm{Z}^{\mathrm{n}}=|\mathrm{Z}|^{\mathrm{n}}[\cos (\mathrm{n} \theta)+\mathrm{i} \cdot \operatorname{sen}(\mathrm{n} \theta)]$, enquanto altera o expoente $\mathrm{n}$ e os parâmetros a e b do número complexo $Z=a+b i$.

Esperamos que o estudante perceba que o vetor que representa a potência de base unitária ganha uma rotação de 90 ㅇ no sentido anti-horário a cada alteração unitária e positiva do expoente $\mathrm{n}$. Esse comportamento pode funcionar como um operador útil em outras áreas do conhecimento.

Ressaltamos que todas as operações representadas nas "caixas de operações" disponibilizadas na tela de animações foram exploradas nos seis itens da Atividade 2 de forma a atender os objetivos da mesma, ou seja, abordar o conteúdo dos números complexos sem aplicações que exija conhecimento de outras áreas do conhecimento.

Atividade 6: aplicação dos números complexos na análise de circuitos RLC com representação fasorial2.

Objetivamos nesta atividade a aplicabilidade das operações matemáticas abordadas na 2a Atividade: soma, subtração, produto escalar de dois vetores, divisão.

Como metodologia, foi desenvolvido um questionário para ser respondido com a observação sobre o que ocorre com os fasores que representam impedância (Z), a tensão (V) e a corrente (i) quando são feitas alterações nos parâmetros dos elementos do circuito. A figura a seguir representa a tela de animações da sexta atividade.

Figura 4 - Tela de animações do OA - Atividade 6. 


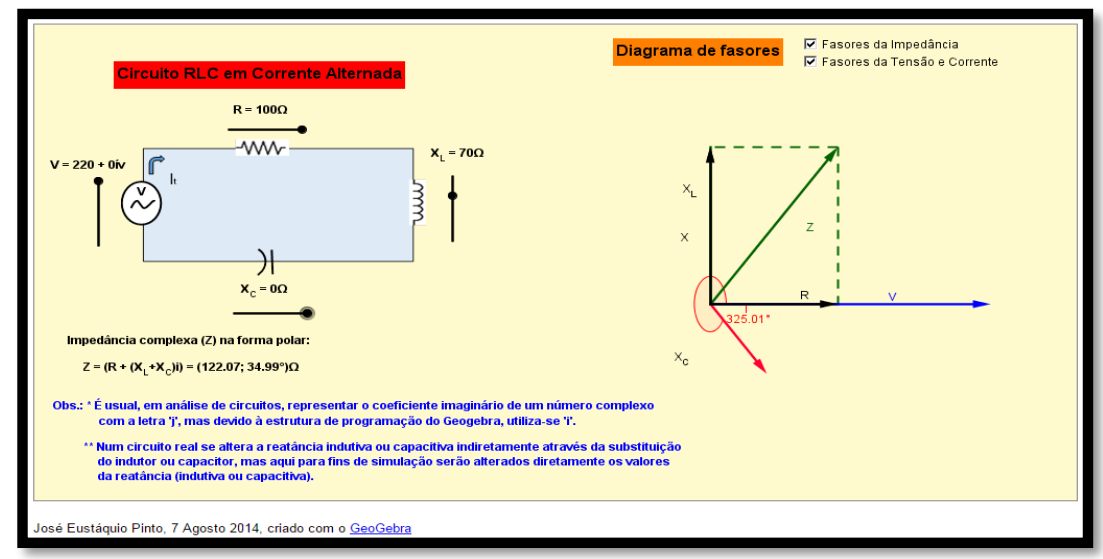

(Fonte: OA Descomplicando os Complexos)

$\mathrm{Na}$ tela de animações da Atividade 6 está representado um circuito RLC de corrente alternada, em série, com a existência de parâmetros que alteram os elementos de impedância e a tensão (V) do circuito. No lado direito da tela, localiza-se um diagrama que representa os fasores que foram programados para serem modificados quando se alteram os parâmetros do circuito.

No canto superior direito da tela, localizam-se caixas de seleção que possibilitam a visualização dos fasores, separadamente, conforme necessidade do item da atividade, podendo ser visualizados separadamente os fasores que representam a impedância ou os fasores, os quais representam a tensão e a corrente do circuito, com o objetivo de "despoluir" a tela para facilitar o entendimento.

Como exemplo, representamos na figura 5 o quinto item Atividade 6. Nessa situação, foi marcada uma opção incorreta e o OA forneceu o feedback ao estudante.

Figura 5 - Segundo item da Atividade 6.

\section{(2) Segundo item.}

Observe o que acontece com os fasores da Tensão e Corrente do circuito e marcue a opcã̃o oue representa a condicão para que o fasor da corrente five em fase com o vetor da tensåa

$(0$ a) Quando $X C>X L$

$O$ b) Quando $X C+X L=0$

$O$ c) Quando $X C<X L$

Od) Quando $X C+X L \neq 0$

Erradal Se necessário, consulte o apoio teórico disponivel.

(Fonte: OA Descomplicando os Complexos)

Esperamos, neste item, que o estudante observe a representação dos fasores da tensão (V) e corrente (I) e entenda, através da dinamicidade geométrica desses fasores, que a condição: $X L+X C=0$ é necessária para que a corrente fique em fase 
com a tensão, ou seja, ambos os fasores representados numa mesma direção e sentido, nesse caso, sobre o eixo real.

\section{ANÁLISE DA APLICAÇÃO}

Para tratar os dados coletados na aplicação das atividades, utilizou-se a análise de erros como metodologia de investigação e avaliação. Para Cury (2013), o trabalho investigativo sobre as respostas pode levar em conta, em um primeiro momento, a tarefa inicial de correção, mas é necessário ter um objetivo na pesquisa, levantando questões que possam ser investigadas. (CURY, 2013, p. 65).

Criamos uma categorização dos erros cometidos pelos estudantes sujeitos da pesquisa. Assim, elencamos quatro tipos de erro:

1ํ - Erro de incompreensão do enunciado: erros relacionados a uma má interpretação do enunciado do item e dos dados presentes no enunciado da atividade disponibilizado na tela do Objeto de Aprendizagem.

2ㅇ - Incompreensão do ambiente informatizado: erros relacionados à dificuldade de manusear ou entender as ferramentas que dinamizam o enunciado dos itens da atividade.

3 - Erros operacionais: são erros relacionados à defasagem de conteúdo, relacionados à manipulação algébrica ou desatenção nos passos de resolução.

4으 - Erros de compatibilidade: erros relacionados à falta de coerência da resposta com os dados dos itens da atividade.

Ressaltamos que, na resolução de cada item, os estudantes poderiam cometer mais de um tipo de erro. Dessa forma, a contagem final leva em conta que pode ter ocorrido mais de um erro no mesmo item.

Apesar do Objeto de Aprendizagem oferecer condições informatizadas para que o estudante possa explorar o próprio erro, seguimos as recomendações de Cury (2013), que enfatiza a importância de explorar os erros, juntamente com os estudantes, fazendo descobertas sobre os conteúdos em questão utilizando o erro, sempre que necessário, para criar estratégias de ensino e retomar os conteúdos nos quais os alunos mostram mais dificuldades. 0 gráfico 1 sintetiza a análise dos erros encontrados nas Atividades 2. 


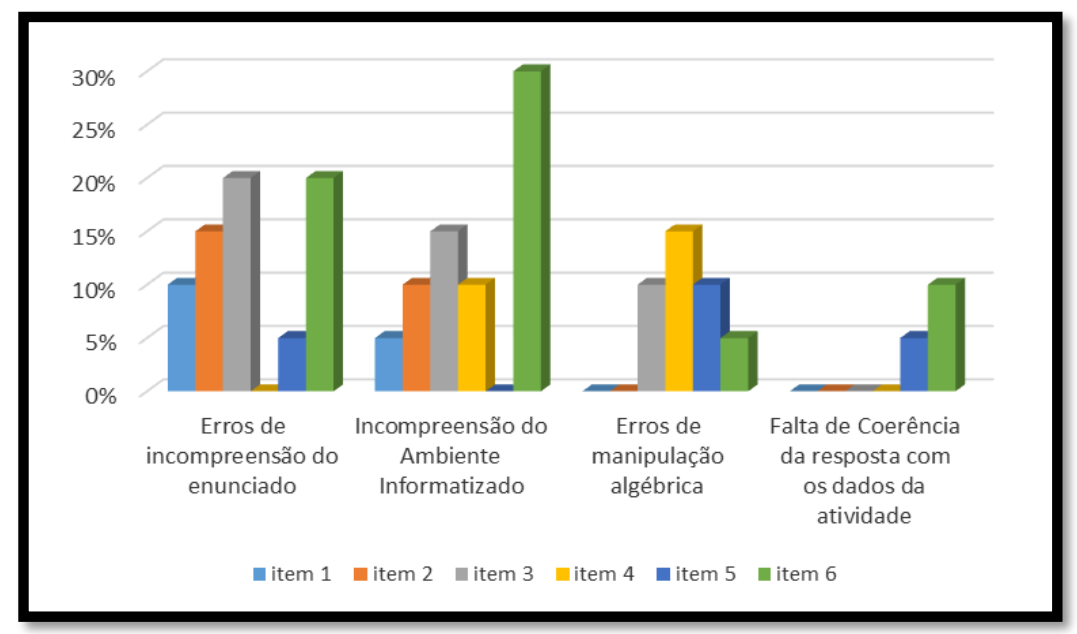

(Fonte: Dados da pesquisa)

No questionário da Atividade 2, elaborado com seis itens, objetivamos contemplar as operações envolvendo os números complexos. Cada item do Questionário tem foco em uma operação específica e explora conceitos e propriedades relacionados, principalmente, ao comportamento geométrico dos números complexos envolvidos.

Nos itens 1 e 2, exploramos os conceitos relacionados à adição e subtração envolvendo números complexos. Quase todos os estudantes acertaram esses itens na primeira tentativa. No terceiro item do Questionário, houve a necessidade da segunda tentativa para que $35 \%$ dos alunos marcassem a resposta correta. No item 3 exigia-se que o estudante explorasse o comportamento geométrico do produto escalar de dois vetores indagando sobre a relação entre o módulo e argumento dos fatores Z1 e Z2 e do produto escalar Z1Z2. Observamos que alguns estudantes não fizeram uso da caixa (ferramenta da tela) que habilita a visualização dos argumentos dos fatores Z1 e Z2. Sem essa informação, os estudantes encontraram dificuldades para inferir que o argumento do produto Z1.Z2 equivale à soma algébrica dos argumentos dos fatores Z1 e Z2.

No quarto item, exploraram-se conceitos relacionados ao comportamento algébrico e geométrico do quociente entre dois números complexos. Apenas $25 \%$ dos estudantes não conseguiram a resposta correta na primeira tentativa.

No quinto item, que explora conceitos relacionados ao comportamento geométrico do vetor que representa a potência de um número complexo, oito estudantes necessitaram da segunda ou da terceira tentativa.

No sexto item, que explora as relações geométricas entre um número complexo e suas respectivas raízes, observamos a situação representada na figura 6 , que ilustra a raiz cúbica do número complexo $Z 1=0+8 \mathrm{i}$. Uma das perguntas exigia-se que os estudantes fizessem inferências entre o módulo de Z1 e o módulo das raízes $(|R k|)$. Embasado num caso específico, conforme a figura a 6 , os estudantes " $E$ " e " $L$ " entenderam que o módulo das raízes de um número complexo é equivalente à raiz cúbica desse número. Desse modo, os estudantes generalizaram esse entendimento, ignorando a possibilidade de outros índices para a raiz de Z1.

Figura 6 - Sexto item da Atividade 2. 


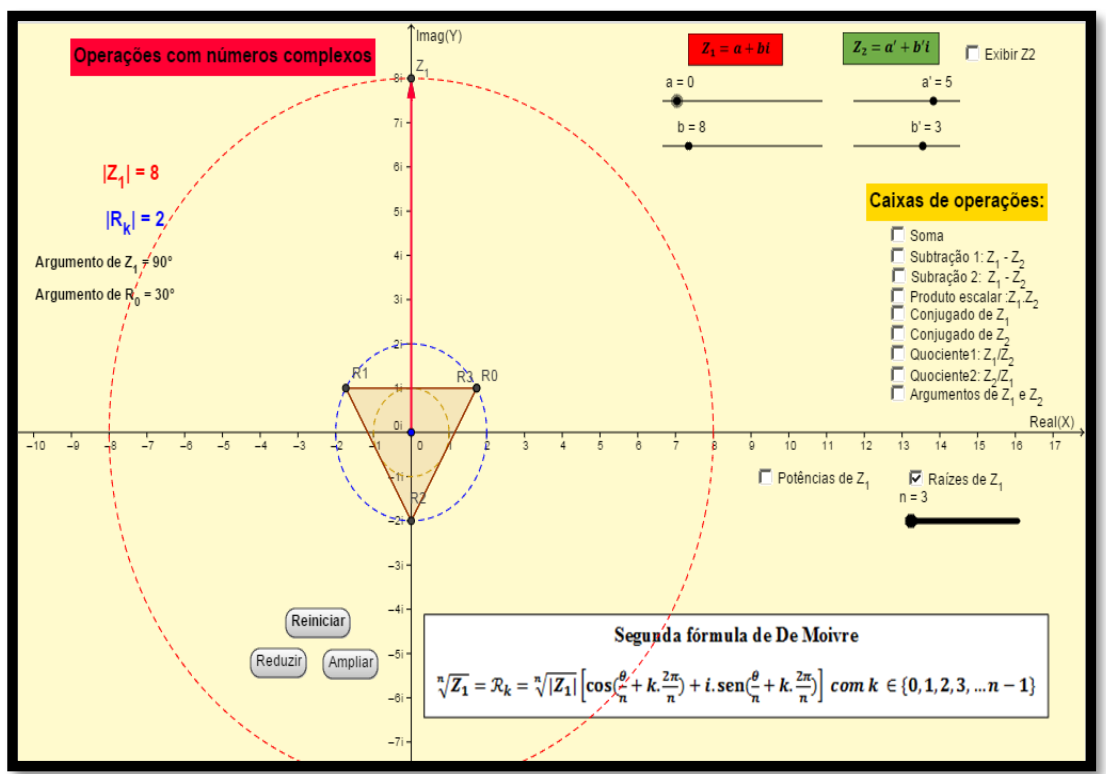

(Fonte: OA Descomplicando os Complexos)

O gráfico 2 sintetiza a análise dos erros encontrados nas Atividades 6 .

Gráfico 2 - Análise de erro da Atividade 6.

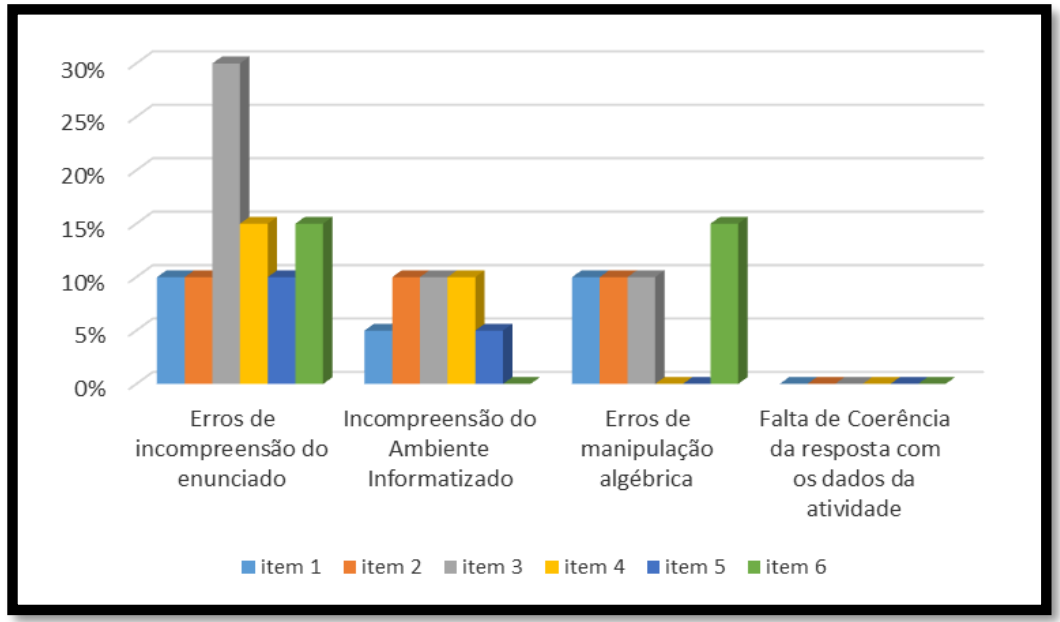

(Fonte: OA Descomplicando os Complexos)

Elaborada com seis itens, a Atividade 6, tem como objetivo ratificar os conceitos adquiridos nas atividades anteriores, porém, com o diferencial da representação dinâmica dos elementos do circuito na forma de fasores.

A tela de animações da Atividade 6 se mostrou eficiente para o objetivo proposto, ao visualizarem a movimentação dos vetores que representam os elementos do circuito, sincronizados com a alteração dos parâmetros dos elementos do mesmo, percebemos que os estudantes encontraram significado nas aplicações que fizeram nas atividades anteriores. Nos dois primeiros itens, mais de $70 \%$ dos estudantes marcaram a opção correta na primeira tentativa. 
Ressaltamos, no terceiro item, que exigia a configuração representada na figura 7, que alguns estudantes confundiram o conceito que determina se um fasor está adiantado ou atrasado em relação a outro. Neste item, o fasor que representa a corrente (i) está adiantado em $45^{\circ}$ em relação à tensão (v), mas $40 \%$ dos estudantes necessitaram da segunda tentativa para acertarem esse item devido terem confundido a posição de atrasado com a posição de adiantamento do fasor.

Figura 7 - terceiro item da Atividade 6.

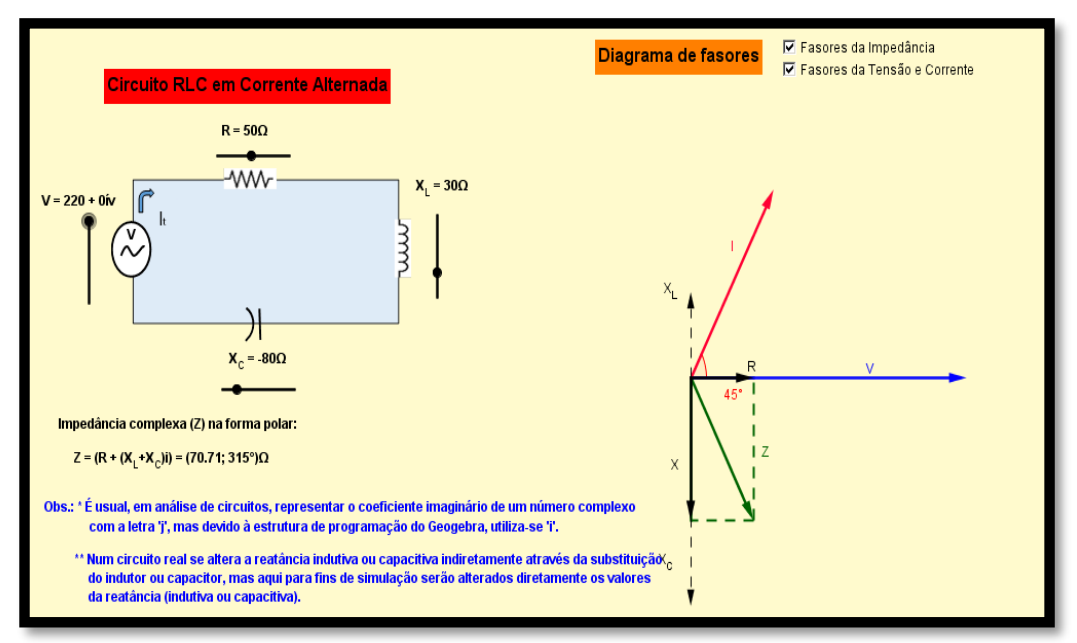

(Fonte: OA Descomplicando os Complexos)

Nos últimos três itens dessa Atividade, percebemos que os estudantes não encontraram dificuldades, uma vez que quase $80 \%$ dos estudantes marcaram a opção correta na primeira tentativa. Vale ressaltar que, no quinto item da Atividade, três estudantes confundiram o conceito de conjugado com oposto de um número complexo e, como havia as duas opções de resposta, esses necessitaram da segunda tentativa para chegarem à opção correta.

\section{CONSIDERAÇÕES FINAIS}

No contexto desta Pesquisa, ao buscar meios e formas processuais de construção de um OA, utilizamos das TICs para dinamizar situações algébricas e, principalmente, geométricas demandadas nas atividades elaboradas no OA. Assim a informática trouxe elementos que permitiram um estudo analítico e sistêmico pelo estudante.

O OA cumpriu o seu papel, uma vez que permitiu ampla comunicação, proporcionando interação entre o professor, os estudantes e as atividades propostas, além de estimulá-los a fazerem experimentações e simulações, de acordo com Moran (2013) e Masetto (2013). O uso da informática educativa por meio do Objeto de Aprendizagem "Descomplicando os Complexos" permitiu a exploração e formalização de propriedades relacionadas às operações com números complexos, a partir da movimentação de pontos e vetores, bem como a representação geométrica das operações. Permitiu também a criação de significado desse conteúdo pelas aplicações na análise de circuitos elétricos. 
Os parâmetros metodológicos e conceituais de Zabala (1998) constituíram a base de edificação das atividades do OA. Preponderaram as características de articulação e estruturação visando atingir uma integração interdisciplinar, com uma proposta didática: números complexos e eletricidade-circuitos.

Para diversificar o método didático, a partir da exclusividade da aula expositiva da pedagogia conservadora, surge uma multiplicidade de propostas para inovar a didática, sendo a sequência didática uma alternativa para planejamento e aplicação fundamentais para construção de inovadores ambientes educacionais.

A nossa proposta didática contribui para diversificação e geração de novos espaços para as aulas do ensino formal do modelo tradicional expositivo. Novos instrumentos para formas de intervenção na realização das aulas.

Ressaltamos que o OA, apresentado neste artigo, juntamente com os outros que estão sendo criados no desenvolvimento do Projeto de Pesquisa citado, estarão num Repositório, específico a abrigar OAs para Educação Profissional Técnica, constituindo um instrumento valioso para os professores de matemática do ensino médio e médio técnico, com atividades de conteúdo teórico e atividades com aplicações. 


\title{
Learning object complexes Numbers with applications in the technical area in electronics
}

\begin{abstract}
In this article, we present results of a survey, supported by the research project "Learning Objects for Teaching of Mathematics at Secondary Technical Vocational Education", public notice $13 / 2012$, financed by FAPEMIG, being developed in the period 2012/2016. The Learning Object, named "Uncomplicated complex", was created in support of professor of mathematics and students of high school and technical courses. It has been structured in six activities, being the first two, without technical applications, in order to attend regular high school students, and the other directed to technical professionals courses with applications in electronics area. It was referenced in theory, Educational Informatics parameters, especially, as the conceptual and methodological purpose of Learning Object and Didactic Sequence. The activities were built based on algebraic and geometric representations of points and vectors that represent complex numbers, in a context of interdisciplinare: Mathematics and Electricity; so the elements of the circuits are analyzed by complex numbers. The results of the experimental application found that the dynamics and interaction of students provided by Learning Object optimized the learning process.
\end{abstract}

KEYWORDS: Computing. Learning Objects. Complex numbers. 
1 Exelearning ou eXeLearning é um editor de código aberto que permite a professores e a acadêmicos a publicação de conteúdos didáticos em suportes digitais sem necessidade de ser ou tornar-se especialista em HTML ou em XML.

2 Fasor: é uma representação gráfica semelhante a um vetor, mas em geral referese a grandezas que variam no tempo como as ondas senoidais.

\section{REFERÊNCIAS}

CURY, Helena Noronha. Análise de erros: o que podemos aprender com os erros dos alunos. 2ำed. Belo Horizonte: Autêntica, 2013.

LAUDARES, João Bosco. Educação Matemática. Belo Horizonte: CEFET-MG, 1987. MASSETO, Marcos Tarciso. Mediação Pedagógica e Tecnologias de Informação e Comunicação. In: MORAN, José Manuel; MASSETO, Marcos Tarciso; BEHRENS, Marilda Aparecida (Org.). Novas tecnologias e mediação pedagógica. 21으 Campinas (SP): Papirus, 2013, p.11-72.

MORAN, José Manuel. Ensino e aprendizagem inovadores com tecnologias audiovisuais e telemáticas. In: MORAN, José Manuel; MASETTO, Marcos T.; BEHRENS, Marilda Aparecida (Org.). Novas tecnologias e mediação pedagógica. 21을 Campinas (SP): Papirus, 2013, p.141-171.

OLIVEIRA, Celina Couto de. Ambientes Informatizados de Aprendizagem: produção e avaliação de software educativo. Campinas : Papirus, 2001.

SPINELLI, Walter. Nem Tudo é Abstrato no Reino dos Complexos. - São Paulo : Seminario de Ensino de Matemática - SEMA/USP, 2009. 11f. disponível em: http://www.nilsonjosemachado.net/sema20091027.pdf. Acesso em: $18 \mathrm{fev}$.

WILEY, David A. Connecting learning objects to instructional design theory: a definition a metaphor, and a taxonomy. 2000. The instructional use of learning objects. Bloomington: Association for Educational Communications and Technology, 2000.2 Disponível em: <http://reusability.org/read/chapters/wiley.doc>. Acesso em: 02 fev. 2014.

ZABALA, Antoni. A Prática Educativa: Como ensinar. Porto Alegre: Artmed, 1998. 


\section{RBECT}

Recebido: 15 out. 2016

Aprovado: 27 out. 2016

DOI: $10.3895 /$ rbect.v9n1.4775

Como citar: PINTO, J. E.; LAUDARES, J. B. Objeto de Aprendizagem de Números Complexos com aplicações na área técnica em eletroeletrônica. Revista Brasileira de Ensino de Ciência e Tecnologia, v.

9, n. 3, 2016. Disponível em: <https://periodicos.utfpr.edu.br/rbect/article/view/4775>. Acesso em: xxx. Correspondência:

Direito autoral: Este artigo está licenciado sob os termos da Licença Creative Commons-Atribuição 4.0 Internacional.

\section{(c) (1)}

